\title{
The temporal and the temporary. Time, collaboration and architecture in post-quake Christchurch
}

\author{
Barnaby Bennett \\ University of Technology Sydney, Australia \\ Faculty of Design, Architecture and Building \\ Barnaby.Bennett@uts.edu.au
}

\author{
Timothy Moore \\ University of Melbourne, Australia \\ School of Design \\ timothym I@student.unimelb.edu.au
}

\begin{abstract}
This paper will look at an apparent tension between master plans that envision cities as finished objects and temporary projects that form in response to more immediate issues and concerns. In the five years since the large earthquake that struck Christchurch on February 22, 20I I, a huge array of interventions, planning decisions, and design proposals have been made -affecting the lives of thousands of people and costing many billions of dollars. These actions are almost always separated into temporal categories of the short-term and the long-term; temporary and the permanent. In this categorisation there is a strange paradox in which the more concrete shortterm actions are characterised as ephemeral and the paper ideas of the long-term more real. The relationship between two forms is complex. Temporary and permanent forms of city-making can be complementary or in conflict - and sometimes both at the same time. Temporary projects can act as stepping-stones to a "finished" city, they can subvert and undermine the long-term plans, and they can support some aspects while undermining others.

The creation of a master plan in Christchurch - 18 months after the earthquakes - will be compared and contrasted with the making of a large temporary project called the Pallet Pavilion. Notions of public engagement strategies, finishing, and risk management will be articulated and used to illustrate how different the modes of temporary and permanent design operate in relation to the construction of the contemporary city.

Concepts from actor network theory will be used to describe the temporary and permanent forms of city-making and different associate types of collaboration. It is argued that the conception and planning of a new city and the design and construction of temporary amenities produce different experiences of time, and different forms of temporality. The authors are PhD candidates researching the role of temporary architecture in contemporary urban settings - this paper reflects on research findings from post-quake Christchurch.
\end{abstract}

Keywords: temporary, transitional, architecture, time, collaboration.

\section{To cite this article:}

Bennett, B., Moore, T. (2017). The temporal and the temporary. Time, collaboration and architecture in post-quake Christchurch. The Journal of Public Space, 2(3), Special Issue, I35- I42, DOI: I0.5204/jps.v2i3.I 22

This article has been peer-reviewed and accepted for publication in The Journal of Public Space. Please see the Editorial Policies under the 'About' section of the journal website for further information.

This work is licensed under a Creative Commons Attribution - Non Commercial 4.0 International License https://creativecommons.org/licenses/by-nc/4.0/ 
66 Temporary measures are vital to create momentum, but not at the cost of removing the imperative to create permanent solutions as quickly as possible." Justin Murray, "In Conversation with Richard McGowan," in Ten Thoughts X Ten Leaders: A Future For Christchurch, Warren and Mahoney, accessed June 20, 2015.

A city is the sum of numerous changing temporary forms of use, which combine to shape the slow, steady evolution of the city as a whole."

Robert Temel, "In the Interim, Everything Changes," in Between Times: Hotel Transvaal Catalyzing Urban Transformation, ed. S. Lindemann and I. Schutten (Amsterdam: SUN Trancity, 2010), 161-168.

In mid-20I2, a year-and-a-half after the "big" February 20II earthquake, the New Zealand government controlled Canterbury Earthquake Recovery Agency (CERA) launched the Christchurch Central Recovery Plan, which included a spatial blueprint for rebuilding the city. The blueprint highlighted eighteen major anchor projects - including a stadium, convention centre, memorial, public parks, and an innovation precinct, to be completed between 2015 and $202 I^{\prime}$. In the interim period - between the earthquake and completion of these long-term projects - hundreds of small temporary, or transitional, projects have been initiated throughout the city to address the immediate concerns of shelter and sanitation, and with more social concerns of places to eat, play, pray and make. ${ }^{2}$ These small projects engage with a temporal condition of waiting - for the master plan to be realised - and provide an opportunity to compare contrasting strategies based on temporary and permanent projects.
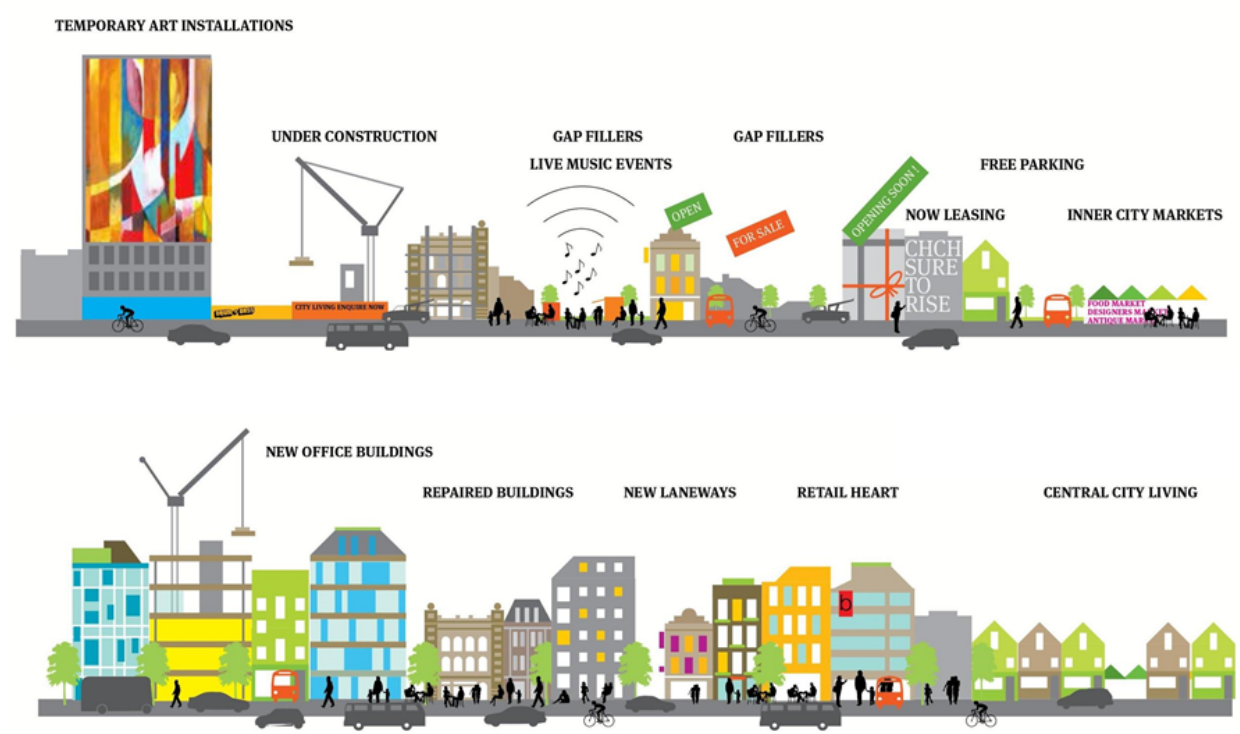

Figure I. The Government's recovery plan compares the "transitional city" and a final permanent form. Images from Christchurch Central Recovery Plan 2012. Owned by the New Zealand Crown and used with Creative Commons Attribution 3.0 New Zealand Licence.

\footnotetext{
' Canterbury Earthquake Recovery Authority (2012). Central City Recovery Plan. Christchurch, Canterbury Earthquake Recovery Authority.

${ }^{2}$ Barnaby Bennett, Eugenio Boidi and Irene Boles. Christchurch: The Transitional City Pt IV (Christchurch: Freerange Press 2013).
} 


\section{Temporality of waiting}

The earthquakes were catastrophic to the functioning of the city and the routines of its inhabitants: schools shut down, landmarks disappeared, relatives moved away, essential services were intermittent, congregational places closed. To respond to the extraordinary disruption legislation was passed - three months after the February quake - in the national parliament that established the legal structure for the recovery, including a requirement for the local city council to develop a draft city plan. ${ }^{3}$ The council engaged Gehl Architects, and worked with the community who responded with over 100,000 ideas for a re-imagined central city in a campaign called Share an Idea. This draft recovery plan was submitted to Christchurch Recovery Minister Gerry Brownlee who considered it for five months before accepting the general principles of the plan, but rejecting the spatial framework and mechanisms for achieving it. Brownlee then invited a consortium of experts to provide a 'blueprint' within one hundred days. This blueprint was launched on the 31 July, 2012 and became law the day after. One critic wrote that "It progressed from a framework that encapsulated a wide range of community ideals to a minister-led masterplan"4. This was a plan that rejected process, public discussion and community collaboration in favour of a finalised form determined by experts, on a tight deadline. The introduction of this 'finished' masterplan to the population created a temporal condition of 'waiting' for it to be realised.

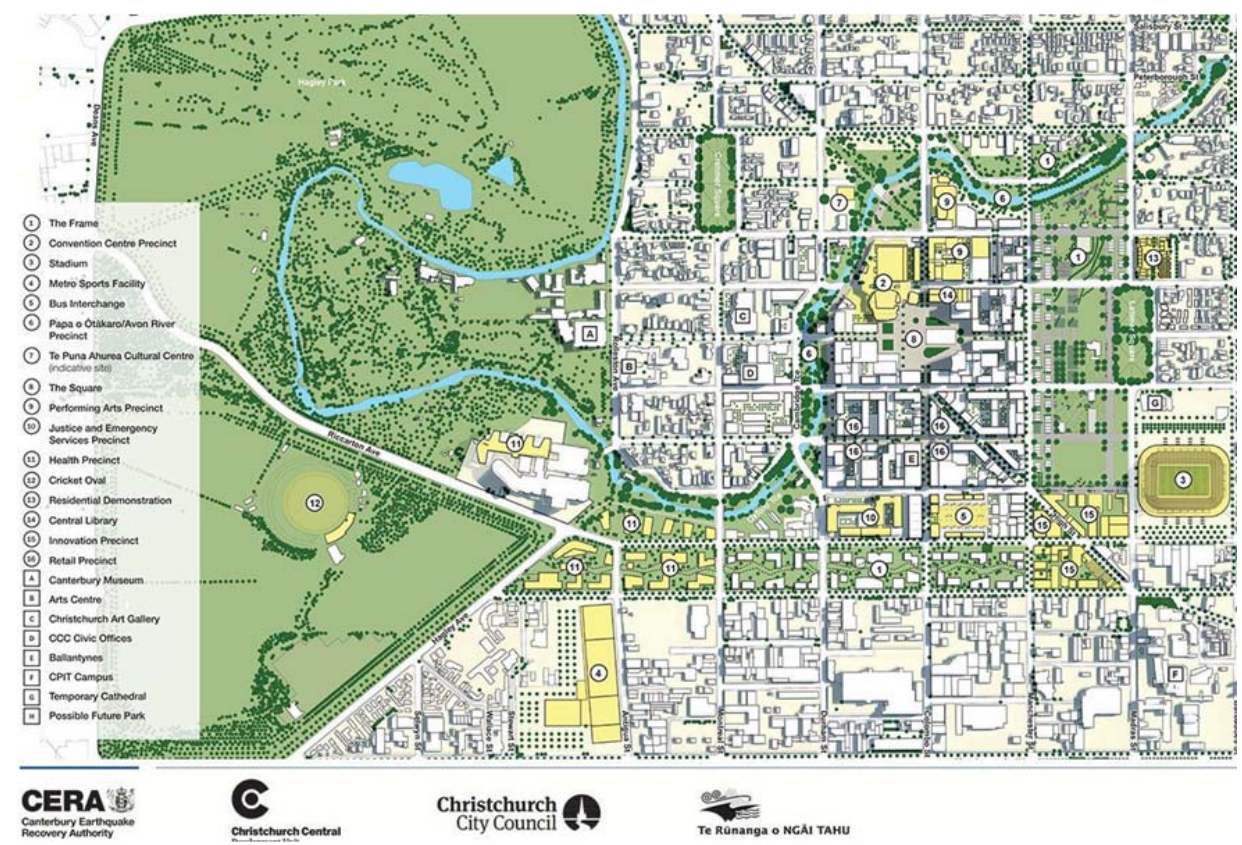

Figure 2: The Government's Central City Blueprint with 18 key anchor projects.

"The Blueprint Plan" Spatial framework as part of the Christchurch Recovery Plan 2012. Owned by the New Zealand Crown and used with Creative Commons Attribution 3.0 New Zealand Licence.

\footnotetext{
${ }^{3}$ Canterbury Earthquake Recovery Act 20II. Accessed 20 June 2015. www.legislation.govt.nz/act/public/201 I/00I2/latest/DLM3653522.html ${ }^{4}$ Barnaby Bennett, Ryan Reynolds, James Dann and Emma Johnson. Introduction to Once in a Lifetime: Citybuilding after Disaster in Christchurch. (Christchurch: Freerange Press, 2014$), 20$.
} 
Geographers Laurent Vidal and Alain Musset claim that waiting has both a temporal and spatial dimension ${ }^{5}$. They argue that 'ordinary spaces can often take on a different social and symbolic meaning' when the activity of waiting in involved. In Christchurch this waiting period created a kind of rupture. Gap Filler co-founder Dr Ryan Reynolds writes about this temporality in the context of the post-earthquake city:

"For more than three years now, Christchurch has been a city completely in transition, almost without a present tense. It is a post city, the remains of the complicated, contradictory, post-colonial place it once was, with a centre that is 70 per cent destroyed and sparsely populated. It is also, now, a precity, with three years' worth of plans, consultation, ideas and designs that exist mainly as a massive set of aspirations yet to be enacted". 6

The notion of permanence inherent in the blueprint - the qualities of stability, durability, endurance, and of things remaining unchanged - fulfils the expectations of contemporary cities as coherent and well-formed places. Permanent form provides homes for long-term institutions, cultural identity, predictability of function, and a stable backdrop for various types of social behaviours.

The loss of the stable and predictable experience of the city after the earthquakes and the idea of waiting - without amenity - several years for a finished version of the city, however was not feasible, possible or bearable to many Cantabrians. "Three to five years is a short time in the life of a city, but quite a long time in the life of a child."7 Waiting suggests a passive experience of time in which action is taking place elsewhere. To wait for something means one is not part of that collaboration of the thing that one is waiting for. Waiting can also be detrimental to the mental health of citizens. Charles Montgomery summarises in The Happy City that participation in geographic and spatial decision-making has real and tangible effects on the health and well-being of citizens. The lost opportunity for improvements in mental health by not being included in these processes is a logical inverse of this. A few months after the large February quake the Science Advisor to the Prime Minister of New Zealand stated that the exclusion of the public from the planning of the city is likely to extend the sense of loss of control that was created by the quakes and negatively impact on its citizens. ${ }^{8}$

\section{Temporality of making}

For people living in the post-disaster setting the experience of waiting has been contrasted with the extensive and pervasive amount of things that needed attention; insurance policies, broken plumbing, difficult roads, and damaged cultural amenity. Adding to these everyday pressures was the need to rebuild and reimagine the city, and citizens

\footnotetext{
${ }^{5}$ Vidal, Laurent, and Alain Musset, eds. Waiting Territories in the Americas: Life in the Intervals of Migration and Urban Transit. Cambridge Scholars Publishing, 2016.

${ }^{6}$ Ryan Reynolds. "Desire for the Gap”, in Once in a Lifetime: City-building after Disaster in Christchurch, (Christchurch: Freerange Press, 2014), 167.

${ }^{7}$ Fran Tonkiss, “Austerity Urbanism and the Makeshift City”, City Vol I7, n. 3 (2013): 3I2-24, 312.

${ }^{8}$ http://www.pmcsa.org.nz/wp-content/uploads/Christchurch-Earthquake-Briefing-Psychosocial-EffectsIOMay II.pdf. Accessed October I, 2017.
} 
were motivated to step up and take part in this process. ${ }^{9}$ The events following the earthquakes provided a window for people rethink how the city is constructed - from how they travel and recycle waste, to how institutions govern, and how buildings are created. These thoughts or questions often turned into scenarios where citizens created temporary projects to respond to unmet demands or imaginations. Many people could not wait; they began to make things, and often they did this in public with other people. The complicated dichotomy between the long-term planning by CERA and the temporary projects led by citizens and citizen-led organisations can be explored through the notion of collaboration in the interim period of waiting. Collaboration is "the action of working with someone to produce something" together. ${ }^{10}$ This conventional definition of collaboration can be expanded by Actor-Network Theory to include collaboration with things such as materials, drawings, institutions, and publics." In this expanded definition collaboration is not just a matter of working with people but becomes a method to understand how different types of collaboration among subjects and objects produce different effects. Thus the conception and planning of a new city, and the design and construction of temporary amenities, are the result of different types of collaboration that in turn produce different experiences, and different experiences of time.

One prominent example of intense collaboration was the Pallet Pavilion, a temporary performance and meeting space initiated by creative urban regeneration initiative called Gap Filler, which occupied a vacant site in the central CBD from October 2012 until May 2014. The Pallet Pavilion was a series of stacked blue pallet-crate walls that enclose a performance space. Gap Filler cited two main reasons for developing this project: first, the immediate and practical concern that there was a shortage of venues in the city; and second, as a demonstrative desire to show that innovative and cheap temporary architecture is possible in responding to post-earthquake demands.

Temporary projects, like the Pallet Pavilion, are "the opposite of the master plan," because they start "from the context and the current condition, not from a distant goal". ${ }^{2}$ A project like this dealt with its immediate context and problems - the need for a performance space with the means and materials directly available. The temporary project was produced by a collection of volunteer experts - such as Architects and project managers - and constructed from borrowed materials.

The resulting project was a combination of: the site of an old hotel on an important diagonal axis in the city, a team of volunteer professionals (architects, designers, builders, contractors), a large group of in-kind and financial sponsorship, around 2000 hours of volunteer labour, roughly 2000 blue shipping pallets, 15 large concrete T-shaped floor slaps, the local council, the fire department, a lighting designer, second-hand plants that were being discarded and inbuilt irrigation system to water them, four portaloos, and much more.

\footnotetext{
${ }^{9}$ John McCrone in The Press. "A temporary long-term solution," Accessed 26 April 2012. www.stuff.co.nz/the-press/news/christchurch-earthquake-201 I/6992/37/A-temporary-long-term-solution 10 "Oxford Dictionary," Oxford University Press, Accessed 20 June 2015. www.oxforddictionaries.com/definition/english/collaboration.

"Bruno Latour, "Technology is Society Made Durable" In J. Law (ed.) "A Sociology of Monsters Essays on Power, Technology and Domination", Sociological Review Monograph 38 (199|): I03-I 32.

${ }^{12}$ Florian Haydn and Robert Temel, Temporary Urban Spaces: Concepts for the use of City Spaces. (Basel, Birkhäuser, 2006), 12.
} 

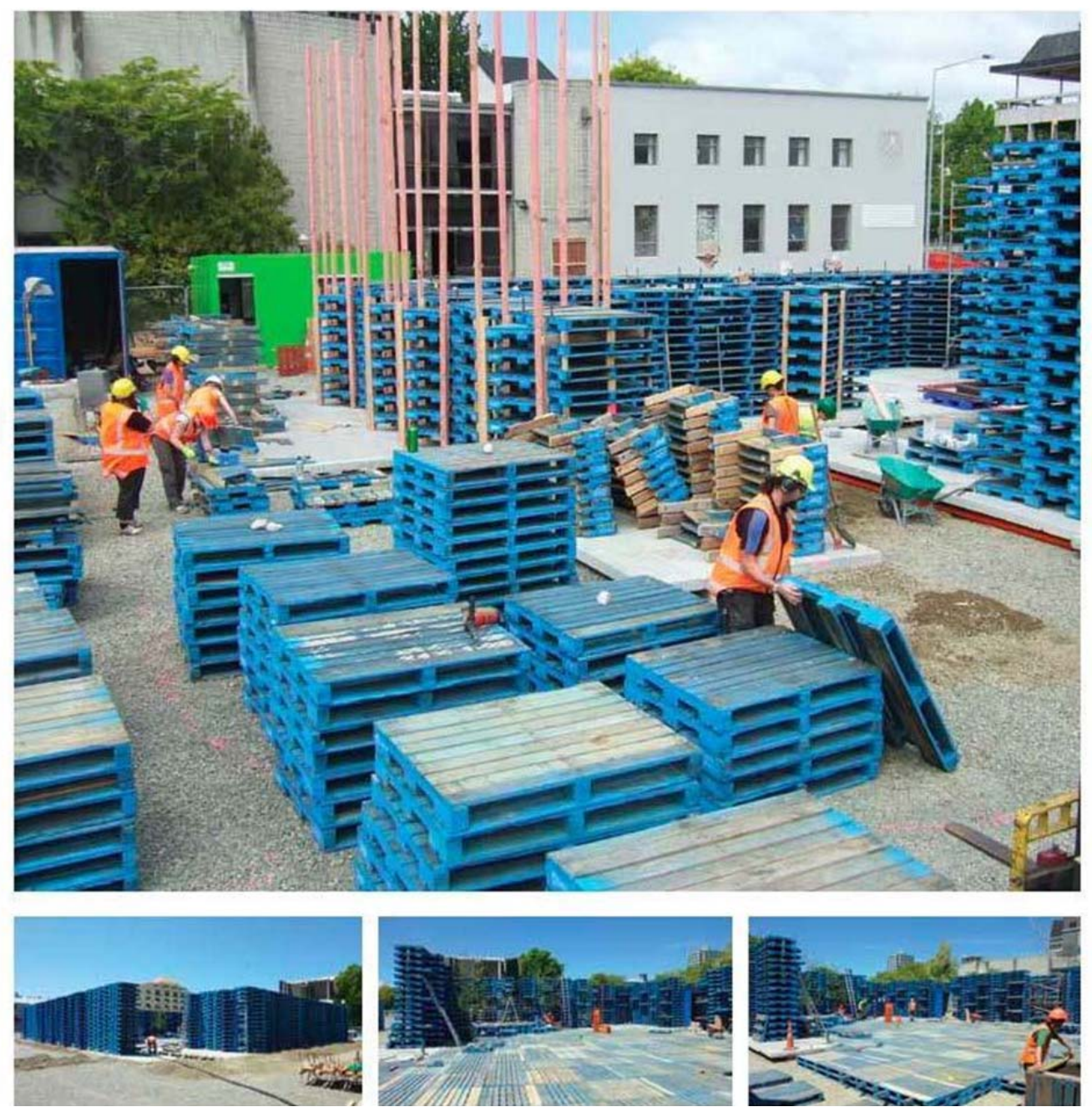

Figure 3: Pallet Pavilion during construction 2012.

Image from the book, Christchurch: The Transitional City, Pt IV. Used with permission of the publisher.

The space became a symbol of an alternative approach to the rebuild: it had hundreds of unique events, gathered tens of thousands of people over 18 months. After its funding ran out after its first year - it was originally planned for one summer - a crowd-funding campaign raised over $\$ N Z 80,000$ to keep it going for another summer.During the design of the Pallet Pavilion an unexpected turn introduced a new series of collaborators. The fire department would only let the project happen on the condition that it have 24-hour site supervision. The need for 24-hour site supervision led to the building being open to the public 24-hours day. This in turn created the space and time for different user groups to access the free amenities of the building. It became the only site in the central city where free water, power, free wifi, and some shelter from the weather that could be accessed by anybody, and subsequently became a place that many different groups used including homeless people with the need for a safe public space to gather.

Actor network theory argues that a full account of a situation requires recognition of the, often disruptive, role that non-human things play in the making of projects. Collaboration is a complex process that requires engagement with both humans and non-human things. 
Physical and material things can enable, thwart, prohibit, suggest, or discourage certain human behaviours and actions. In novel situations with new collaborations, unconventional environments, or different materials, the consequences can unpredictable. The challenge in these circumstances is to keep collaborate processes open so the project can adapt to surprises, but this also introduces shifts and adaptations not expected in longer term forecasts. By using temporary projects to fill in the time of waiting, with a time of making, new, unexpected and often productive forms of citymaking can emerge.

\section{The differences for design}

At first glance the permanent projects planned by CERA appear to be the antithesis of the temporary projects. They work across different scales, economies, time-frames and levels of expertise. The large-scale projects are costly, long-term and slow to build - developed in a complex assemblage across different time-zones and and multiple consultancy teams who are paid handsomely for their time. The bulky structures will emerge in reinforced concrete, steel and glass. Temporary projects are small-scale, quick, cheap, and often rely upon local volunteer labour. While they seem like stable propositions, the planned "permanent" project may not always eventuate. (By the middle of 2016 only three of the eighteen anchor projects had been completed.) The temporary often lasts much longer than anticipated. An analysis of 185 temporary projects in the book Christchurch: The Transitional City shows the temporary project lasted, on average, almost twice as long as anticipated. While temporary and permanent urban projects are defined by their different time scales, this shift in thinking around permanence indicates a number of ways in which materials, labour, and other things can be considered, and this in turn changes the way designers relate to them. This difference can be viewed through three categories: strategies for public engagement, finishing, and risk management.

Firstly, the various scales of the projects reveal different strategies for public engagement. The relatively short time-frame and small scale of temporary projects sees the distance of makers and users contract. In the temporary projects "the designer remains embedded with their public and that responsibility becomes a shared one, and one that gives space for the designer to usefully contribute their expertise while engaging users in taking on and continuing to develop results". ${ }^{3}$ This is evident at the Pallet Pavilion where the use of volunteer labour and construction materials saw many people from the wider community incorporated in the decision-making process of the project.

Secondly, a permanent project is considered finished when it is opened while a temporary project is finished when its use comes to an end. If something is unfinished, it can still be changed; in some circumstances, this change is invited. Finished buildings often treat change and alteration as a threat requiring great expense and more lost time. These forms are crystallised long before the public becomes engaged in their use. The potential of the unfinished project is evident with the Pallet Pavilion was conceived to last for one summer the issue of the materials at the end of that summer led to new collaborations.

${ }^{13}$ Guy Julier, "From Design Culture to Design Activism", The Journal of the Design Studies Forum Vol. 5, n. 2 (2013): $215-236,230$. 
The pavilion was only finished once it was carefully deconstructed and its parts returned to the supply chains from where they came: the pallets to the shipping company, furniture deconstructed to vegetable boxes and the concrete foundations donated to farmers to use as bridges. While the public was waiting for the finished project, they were also actively participating in the life of the unfinished project, and an unfinished city. Thirdly, each type of collaboration creates different risk management approaches. Permanent projects manage large financial and technological risks. Collaborations among experts are preferred to collaboration with citizens. The temptation for designers on large projects is to favour strategies that design out the risks involved of working with unpredictable actors. Temporary projects do not have the same pressures and offer different opportunities. For example the lack of a roof in the pallet pavilion led to the need to engage with the weather. On some nights this was difficult and led to rain and cancellations. On others it created circumstances not possible in conventional venues such as a performance under a moonrise or colourful lighting reflecting of the rain as it bounced of drum skins on the final night. The presence of the rain, the sun, the wind and the moon at times made the management of the venue difficult, but it also reminded the users of the space of various movements of weather and cycles of time that cities often act to remove because they are seen as threats to efficiency and safe management of assets.

The degrees of public engagement, finishing, and risk management reveal different levels of bringing networks of people (or publics) into projects. By becoming agents in an ongoing design processes, citizens - with other collaborators - develop greater agency to negotiate with the forces that influence their built environment.

\section{Conclusion}

This essay proposes that the difference between temporary and permanent architecture can be understood in the way that different collaborations gather together to co-produce the built environment. One of the effects of temporary architecture is that it highlights and questions practices that produce other, more permanent, forms. While the processes that produce large-scale plans and more permanent forms tend to be ones of closing down broad collaborations with the public once a form is constructed, in contrast the temporary continues to open up opportunities for engagement and change. By creating a brief comparative case study analysis that contrasts a temporary project with a permanent plan it contributes to a global conversation about the role of place-making, temporary architecture and citizen led interventions into public space.

Temporary projects, such as the pallet pavilion, shift the role of the public from a passive agent that is consulted during design and that uses a building after construction to a more meaningul role as an ongoing and active participant - collaborator - in the creation of events and procedures in the ongoing life of buildings and cities. Perhaps the opportunity of these temporary post-quake projects is a movement towards a type of design, a form of public space, and a different way of making buildings in which the public is more carefully and cleverly represented and kept visible. 